Atmos. Chem. Phys., 14, 1689-1700, 2014

www.atmos-chem-phys.net/14/1689/2014/

doi:10.5194/acp-14-1689-2014

(c) Author(s) 2014. CC Attribution 3.0 License.

\title{
The role of low volatile organics on secondary organic aerosol formation
}

\author{
H. Kokkola ${ }^{1}$, P. Yli-Pirilä ${ }^{2}$, M. Vesterinen ${ }^{1}$, H. Korhonen ${ }^{3}$, H. Keskinen ${ }^{2}$, S. Romakkaniemi ${ }^{2}$, L. Hao ${ }^{2}$, \\ A. Kortelainen ${ }^{2}$, J. Joutsensaari ${ }^{2}$, D. R. Worsnop ${ }^{2,4}$, A. Virtanen ${ }^{2}$, and K. E. J. Lehtinen ${ }^{1,2}$ \\ ${ }^{1}$ Finnish Meteorological Institute, P.O. Box 1627, 70211, Kuopio, Finland \\ ${ }^{2}$ University of Eastern Finland, P.O. Box 1627, 70211, Kuopio, Finland \\ ${ }^{3}$ Finnish Meteorological Institute, P.O. Box 503, 00101, Helsinki, Finland \\ ${ }^{4}$ Aerodyne Research Inc., Billerica, MA 01821-3976, USA
}

Correspondence to: H. Kokkola (harri.kokkola@ fmi.fi)

Received: 16 May 2013 - Published in Atmos. Chem. Phys. Discuss.: 4 June 2013

Revised: 3 January 2014 - Accepted: 13 January 2014 - Published: 14 February 2014

\begin{abstract}
Large-scale atmospheric models, which typically describe secondary organic aerosol (SOA) formation based on chamber experiments, tend to systematically underestimate observed organic aerosol burdens. Since SOA constitutes a significant fraction of atmospheric aerosol, this discrepancy translates into an underestimation of SOA contribution to radiative forcing of atmospheric aerosol. Here we show that the underestimation of SOA yields can be partly explained by wall losses of SOA forming compounds during chamber experiments. We present a chamber experiment where $\alpha$-pinene and ozone are injected into a Teflon chamber. When these two compounds react, we observe rapid formation and growth of new particles. Theoretical analysis of this formation and growth event indicates rapid formation of oxidized volatile organic compounds (OVOC) of very low volatility in the chamber. If these oxidized organic compounds form in the gas phase, their wall losses will have significant implications on their partitioning between the gas and particle phase. Although these OVOCs of very low volatility contribute to the growth of new particles, their mass will almost completely be depleted to the chamber walls during the experiment, while the depletion of OVOCs of higher volatilities is less efficient. According to our model simulations, the volatilities of OVOC contributing to the new particle formation event can be of the order of $10^{-5} \mu \mathrm{g} \mathrm{m}^{-3}$.
\end{abstract}

\section{Introduction}

Organic chemical compounds modify the physical and chemical properties of atmospheric aerosol particles, namely, their radiative properties, their ability to act as cloud condensation nuclei, and heterogeneous chemistry. Organic compounds (OC) amount to a significant fraction of atmospheric aerosol mass. In several observations at different types of locations, the measured mass fraction of organic compounds can be 20-90\% in collected aerosol samples (Jimenez et al., 2009). Thus, OC has a major role in the climate effects of global atmospheric aerosol.

Organic aerosol can be emitted directly into the atmosphere as primary particles, e.g. from fossil fuel and biomass combustion, or it can be of secondary origin; when volatile organic compounds (VOC) are oxidized in the atmosphere, they produce oxidized volatile organic compounds (OVOC) which condense onto pre-existing aerosolforming secondary organic aerosol (SOA). SOA compounds affect the size distribution, radiative properties, and cloud activation properties of atmospheric particles. Thus, their contribution to the global aerosol mass and composition play a key role in the climate effects of the atmospheric aerosol. In current global aerosol-climate models the SOA description is based on oxidation chamber experiments (bottom-up approach). A bottom-up approach tends to underestimate the global burden of SOA when compared to the observations or compared to studies where global SOA burdens are determined inversely based on VOC 
emission data and estimates of SOA removal (top-down approach) (Jimenez et al., 2009; Goldstein and Galbally, 2007; Hallquist et al., 2009). The magnitude of this underestimation can be more than one order of magnitude and may lead to significant errors when predicting global aerosol forcing (Goldstein and Galbally, 2007; Hallquist et al., 2009).

A major difficulty in modeling SOA formation accurately is that the chemical composition and formation pathways of condensing organic compounds that take part in SOA formation are still mostly unknown. Another difficulty is that their volatility undergoes continuous change in the atmosphere for several days (Kroll and Seinfeld, 2008). Information on the volatility is of crucial importance since OVOCs of low volatility (LVOC) have an important role when the freshly nucleated particles grow to sizes that can form cloud droplets (Riipinen et al., 2011). A recent study has also shown that oxidized organics can be involved in the aerosol nucleation process itself (Zhao et al., 2013). Until recently, it was believed that the formation of LVOCs via gas-phase oxidation of emitted VOCs takes several hours in the atmosphere (Jimenez et al., 2009).

The very large number of chemical compounds involved in SOA formation processes makes it a challenging task to calculate the concentration of specific oxidation products. Even explicit chemistry models have great uncertainties in predicting the oxidation state of ambient SOA precursors (Ceulemans et al., 2012). However, they are computationally too demanding to be coupled to models that describe SOA concentrations on a regional- or global scale. To overcome this complexity, simplified methods have been developed to describe OVOCs that are involved in the formation of SOA. A common way is to categorize different organic compounds according to their volatility, i.e. their saturation vapor pressure. Two commonly used methods include treating SOA precursors as two model compounds of different volatilities (Odum et al., 1996) or separating the precursors into several classes according to their volatilities, namely the Volatility Basis Set (VBS) (Donahue et al., 2006).

The mass yields of SOA are often based on chamber measurements: the yields are obtained by analyzing the observed increase in condensed particulate mass when a known amount of VOCs are oxidized in the chamber (Donahue et al., 2006; Pathak et al., 2007a; Meyer et al., 2009; Duplissy et al., 2011). To get information on the yields of individual volatility classes, data from aerosol particle sizers, aerosol mass spectrometers, and thermodenuders are combined to analyze the oxidation state and the volatilities of condensed compounds.

One complication in these experiments is the loss of aerosol on the chamber wall surfaces during an experiment. The measured particulate mass is affected by losses of particles to the chamber walls and the mass yields have to be corrected accordingly (Pathak et al., 2007b). Recently, it has also been acknowledged that the wall losses of the gas phase compounds, i.e. SOA precursors, can have a significant ef- fect on the SOA yields and have to be accounted for when the SOA yields are estimated (Pathak et al., 2007a; Pierce et al., 2008; Matsunaga and Ziemann, 2010; Loza et al., 2010).

Whereas the chamber walls act as a continuous sink for the aerosol particles, Matsunaga and Ziemann (2010) showed that, for organic compounds, an equilibrium forms between the walls and the gas phase. They suggested a method to calculate the partitioning between the walls and the gas phase as equilibrium using an analogue of Henry's law equilibrium. According to their theoretical framework, the fractions of different OC partitioned on the walls are determined by the equation

$\frac{[\mathrm{OC}]_{\mathrm{w}}}{[\mathrm{OC}]_{\mathrm{T}}}=\frac{K_{\mathrm{p}}}{\left(K_{\mathrm{p}}+1\right)}$,

where $[\mathrm{OC}]_{\mathrm{W}}$ is the number of moles of $\mathrm{OC}$ on the wall, $[\mathrm{OC}]_{\mathrm{T}}$ is the total number of moles of OC in the chamber, and $K_{\mathrm{p}}$ is the partitioning coefficient. The partitioning coefficient $K_{\mathrm{p}}$ can be calculated according to

$K_{\mathrm{p}}=K_{\mathrm{w}} C_{\mathrm{w}}=\frac{R T C_{\mathrm{w}}}{M_{\mathrm{w}} \gamma_{\mathrm{w}} P^{\circ}}$,

where $K_{\mathrm{w}}$ is the gas-wall partition coefficient, $C_{\mathrm{w}}$ is the effective concentration of absorbing mass, $R$ is the gas constant, $T$ is temperature, $M_{\mathrm{w}}$ is the molar mass of OC, $\gamma_{\mathrm{w}}$ is the OC activity coefficient for the Teflon wall (assumed 1 in this study), and $P^{\circ}$ is the saturation vapor pressure of OC.

Formation of such an equilibrium state will have significant consequences on SOA formation as the OVOCs would strive to reach simultaneous equilibrium between the particles, the gas phase, and the walls (see Fig. 1). For example, if the condensation of OVOCs to the particles depletes them from the gas phase, OVOCs already deposited on the chamber walls will evaporate to maintain the gas-wall equilibrium. This makes it more complex to account for the wall losses of OVOCs during a chamber experiment compared to an approach where gas deposition to the wall is considered irreversible. Another difficulty related to this method is that the equilibrium is dependent on the wall-partitioning properties of each chemical compound. If this approach is used to account for the wall losses for all oxidation products of VOCs, the wall-partitioning properties in Eq. (1) should be quantified for each individual compound. Therefore, to apply this method together with e.g. the volatility basis set, the wall-partitioning properties of each volatility class should be defined.

Here we study the implications of the equilibrium gas-wall partitioning on the estimated SOA yields in a set of Teflon chamber experiments. First, we use high-resolution proton transfer reaction mass spectrometry (PTR-MS) to estimate the gas-wall partitioning of $\alpha$-pinene and two of its oxidation products, and then formulate a generalized function of partitioning for oxidation products of $\alpha$-pinene as a function of saturation vapor pressure. We apply this partitioning function in an aerosol microphysics model and compare model 


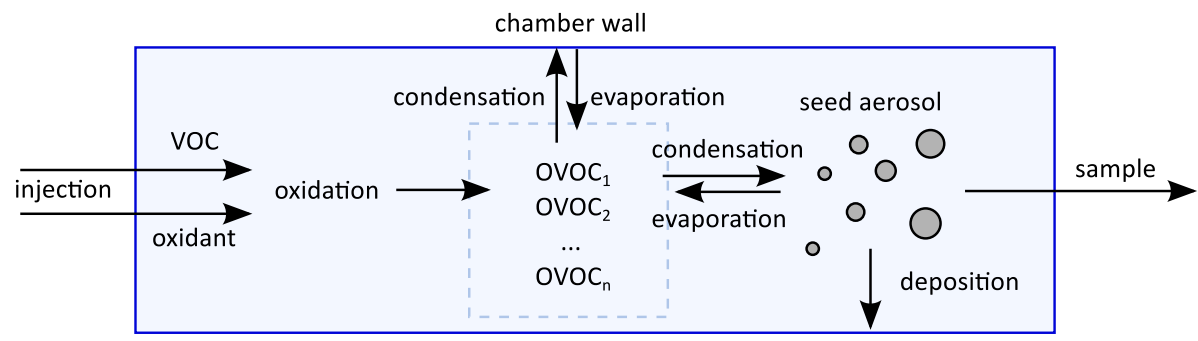

Fig. 1. Schematic of processes modifying the concentrations of particle and gas phase organics during an oxidation chamber experiment

results against chamber measurements of aerosol formation and growth to estimate the implications of gas wall losses on the SOA yields. The schematic in Fig. 1 illustrates the processes involved in the aerosol formation and growth experiment, which are solved in the model concurrently. In this experiment a VOC ( $\alpha$-pinene) and an oxidant $\left(\mathrm{O}_{3}\right)$ are injected in a chamber with pre-existing seed aerosol.

\section{Materials and methods}

\subsection{Gas-wall equilibrium partitioning}

In the first Teflon chamber experiment, the gas-wall partitioning of organic gases was quantified by injecting three organic gases of different volatilities into the chamber and measuring the gas phase concentration after injection. The chamber setup has been described in detail by Hao et al. (2011). Briefly, the system consists of precursor and seed particle injection systems, a reaction chamber (made of FEP film, volume $4 \mathrm{~m}^{3}$ ), and gas and particle measurements systems. The injected OC were pinanediol, nopinone and $\alpha$-pinene, whose saturation vapor pressures are $0.533 \mathrm{~Pa}\left(3.73 \times 10^{4} \mu \mathrm{g} \mathrm{m}^{-3}\right), 53.6 \mathrm{~Pa}(3.04 \times$ $\left.10^{6} \mu \mathrm{g} \mathrm{m}^{-3}\right)$ and $465.15 \mathrm{~Pa},\left(2.60 \times 10^{7} \mu \mathrm{g} \mathrm{m}^{-3}\right)$, respectively (www.chemspider.com). Nopinone and pinanediol were chosen for this study since they are probable oxidation products of $\alpha$-pinene. Experiments were performed in the absence of seed particles at a relative humidity below $5 \%$. The chamber was kept at constant room temperature $(20 \pm$ $1{ }^{\circ} \mathrm{C}$ ) during the experiment. Before each experiment, the chamber was flushed continuously with purified dry air for about $48 \mathrm{~h}$ to ensure minimal contamination from previous experiments. A known amount of $\alpha$-pinene (SigmaAldrich, $99 \%$ ), nopinone (Sigma-Aldrich, $98 \%$ ) and pinanediol (Sigma-Aldrich, 99\%) were first dissolved in methanol (Fisher Chemicals, HPLC grade) and then added to the chamber by injecting the liquid into a stream of purified air. The injection port, the short inlet line $(10 \mathrm{~cm})$ and the air were heated to $60^{\circ} \mathrm{C}$ to minimize losses during the injection. Each VOC injection lasted two minutes. During that time liquid VOC was slowly introduced with a microliter syringe into the stream of heated air.
The gas phase concentration in the chamber was monitored using a high-resolution proton transfer reaction mass spectrometer (PTR-TOF-MS 8000, Ionicon Analytik, Innsbruck, Austria). Sample air from the chamber was introduced to the PTR drift tube via a $1.5 \mathrm{~m}$-long heated $\left(60^{\circ} \mathrm{C}\right)$ PEEK tubing (outer diameter $0.1 \mathrm{~cm}$ at a flow rate of $160 \mathrm{~mL} \mathrm{~min}^{-1}$ ). PTR-TOF-MS was operated under controlled conditions $(2.3 \mathrm{mbar}$ drift tube pressure, $600 \mathrm{~V}$ drift tube voltage and $60^{\circ} \mathrm{C}$ temperature). The sensitivity of PTRMS for the studied compounds was calibrated using the gas phase concentration results from Tenax TA samples. Within $30 \mathrm{~min}$ after the injection, the gas phase concentration in the chamber had stabilized and VOC samples were collected onto $200 \mathrm{mg}$ of Tenax TA adsorbent (Supelco, mesh 60/80) for 10 to $30 \mathrm{~min}$ with an air flow of $220 \mathrm{~mL} \mathrm{~min}^{-1}$ through the sample tube. The sampling time depended on the injected concentration, so that for the lowest concentration the sampling time was the longest in order to obtain a high enough amount of VOC for the analysis. Tenax TA adsorbent was connected directly to the chamber without any sample line to reduce wall losses during sampling. The trapped compounds were desorbed from the collected VOC samples with a thermal desorption unit (Perkin-Elmer ATD400 Automatic Thermal Desorption system) and analyzed with a gas chromatograph-mass spectrometer (Hewlett-Packard GC 6890 and MSD 5973). A detailed description of the VOC analysis is given by Vuorinen et al. (2004). In order to avoid significant formation of particles, the concentrations of the injected compounds were kept beneath the saturation concentration of the vapors. To affirm low new particle formation, the particle concentrations were continuously measured with a condensation particle counter (CPC3010, TSI).

\subsection{SOA formation experiment}

The dynamics of organic aerosol formation, and in particular the implications of measured wall losses of SOA precursors were studied in an $\alpha$-pinene ozonolysis experiment in the presence of seed aerosol. As the seed aerosol, we used polydisperse ammonium sulphate particles which were generated from a salt solution by using an aerosol generator (Model 3076, TSI Inc., USA). The ammonium sulphate content in the water suspension was $1 \mathrm{wt} \%$. The produced aerosol was 
fed to a diffusion drier (porous tube surrounded by silica gel), resulting in relative humidity $(\mathrm{RH})$ below $5 \%$ (RH sensor, Rotronic).

After introducing the seed aerosol to the flushed Teflon chamber, its concentration was diluted to $\sim 10^{4} \mathrm{~cm}^{-3}$. Next, $2 \mu \mathrm{L}$ of $\alpha$-pinene was injected into the chamber and left to mix for $15 \mathrm{~min}$. Based on the injected amount and the volume of the chamber, the initial concentration of $\alpha$-pinene was $450 \mu \mathrm{g} \mathrm{m}^{-3}$. Next, ozone-enriched air (1.5 ppm, generated with a UV lamp $\mathrm{O}_{3}$ generator) was introduced into the chamber at $30 \mathrm{~L} \mathrm{~min}^{-1}$ to achieve an ozone concentration of $50 \mathrm{ppb}$. The ozonolysis of $\alpha$-pinene resulted in a distinct nucleation and growth event which was monitored with two scanning mobility particle sizers (SMPS: SMPS1: CPC3027 \& DMA 3075; SMPS2: CPC 3022 \& DMA 3071) with measurement ranges from $8-60 \mathrm{~nm}$ and $10-700 \mathrm{~nm}$, respectively. The temperature during the experiment was $25 \pm 2{ }^{\circ} \mathrm{C}$ and $\mathrm{RH}$ $5 \pm 2 \%$.

Real-time chemical composition in the particles with vacuum aerodynamic diameter size ranging from 50 to $1000 \mathrm{~nm}$ was measured using Aerodyne HR-TOF-AMS (High Resolution Time-Of-Flight Aerosol Mass Spectrometer) (Jayne et al., 2000; DeCarlo et al., 2006) using standard $600^{\circ} \mathrm{C}$ vaporizer temperature. Sulphate, organics, ammonium and nitrate mass loadings were determined by AMS. O:C ratios were determined by AMS elemental analysis as described by Aiken et al. (2008).

\subsection{Chamber model}

The evolution of the aerosol size distribution during the SOA formation experiment was simulated using a modified version of the sectional aerosol model SALSA (Kokkola et al., 2008). The model solves condensation, coagulation, hydration, and nucleation. In its default configuration, it describes aerosol size distribution using 10 size sections. In this study, we increased the size resolution to 25 size sections.

When using the default configuration of SALSA, the chemical compounds in the model are sulphate, sea salt, organic carbon, black carbon and mineral dust. In this study, we extended the model to include organic compounds according to the volatility basis set. Semi-volatile organic compounds (SVOC) with seven different volatilities were introduced to the model. Partitioning of each individual SVOC between the gas and the particle phase was calculated according to the Analytical Predictor of Condensation method (Jacobson, 2005). The method solves the condensation equation

$$
\frac{\mathrm{d} C_{\mathrm{org}, i}}{d t}=k_{\mathrm{m}, i}\left(C_{\mathrm{org}, i, \text { surf }}-C_{\mathrm{org}, \mathrm{gas}}\right)
$$

for organic compound "org" and size section $i$. In Eq. (3), $k_{\mathrm{m}, i}\left(\mathrm{~s}^{-1}\right)$ is the mass transfer coefficient, $C_{\mathrm{org}, i, \text { surf }}$ is the equilibrium concentration of a condensing organic compound at the particle surface, and $C_{\text {org,gas }}$ is the gas phase concentration of the condensing compound. The saturation
Table 1. Saturation concentrations $C^{*}\left(\mu \mathrm{g} \mathrm{m}^{-3}\right)$ and corresponding stoichiometric coefficients $\alpha$ for VBS classes.

\begin{tabular}{lrrrrrrr}
\hline$C^{*}$ & 0.01 & 0.1 & 1.0 & 10 & 100 & 1000 & 10000 \\
$\alpha$ & 0.001 & 0.012 & 0.037 & 0.088 & 0.099 & 0.250 & 0.80 \\
\hline
\end{tabular}

concentration at the droplet surface is calculated using the equation

$C_{\mathrm{org}, i, \mathrm{surf}}=S^{\prime} C_{\mathrm{org}, i, \mathrm{surf}}=S_{i}^{\prime} x_{\mathrm{org}, i} C_{\mathrm{org}, \mathrm{sat}}$,

where $S_{i}^{\prime}$ is the Kelvin effect, $x_{i}$ is the mole fraction, and $C_{\text {org,sat }}$ is the saturation concentration of the condensing compound. It should be noted that we assume the condensing organic compounds to behave as ideal compounds in the condensed phase, similarly to Pierce et al. (2011).

The model was also extended to include gas phase ozonolysis of $\alpha$-pinene. The gas phase production rate for each condensing organic was assumed to be

$\frac{\mathrm{d} C_{\text {org,gas }}}{\mathrm{d} t}=\alpha_{\mathrm{org}} k_{\mathrm{O}_{3}} C_{\mathrm{O}_{3}} C_{\alpha \text { pinene }}$,

where $C_{\text {org,gas }}$ is the concentration and $\alpha_{\text {org }}$ is the stoichiometric coefficient of the condensing organic compound, $k_{\mathrm{O}_{3}}$ is the reaction coefficient for the oxidation reaction with value of $5.4 \times 10^{-15} \mathrm{~cm}^{-3} \mathrm{~s}^{-1}$ (Atkinson and Arey, 2003). The values for stoichiometric coefficients are given in Table 1 .

The loss rates for ozone and $\alpha$-pinene due to oxidation reaction are assumed to be

$\frac{\mathrm{d} C_{\mathrm{O}_{3}}}{\mathrm{~d} t}=\frac{\mathrm{d} C_{\alpha \text { pinene }}}{\mathrm{d} t}=-k_{\mathrm{O}_{3}} C_{\mathrm{O}_{3}} C_{\alpha \text { pinene }}$,

where $C_{\mathrm{O}_{3}}$ and $C_{\alpha \text { pinene }}$ are the concentrations of ozone and $\alpha$-pinene, respectively.

The gas phase reaction Eqs. (5) and (6) for all compounds involved in the reactions were solved using an ordinary differential equation solver (Radhakrishnan and Hindmarsh, 1993).

Particle wall losses were determined by seeding the chamber with a polydisperse distribution of ammonium sulfate particles in the absence of condensing vapors and measuring the time evolution of the size distribution. Particle wall losses for number concentrations $N_{i}$ in each size section $i$ were assumed to have a functional form of

$\frac{\mathrm{d} N_{i}}{\mathrm{~d} t}=\sum_{n=0}^{5} A_{n} d_{\mathrm{p}}^{n} N_{i}$

where $d_{\mathrm{p}}$ is the particle diameter (in nm). Parameters $A_{n}$ are given in Table 2 and obtained in the following way: the parameters for the function were optimized so that the model reproduces the measured wall losses for all sizes. This way, the particle losses due to coagulation are excluded in the loss 
Table 2. Parameters for wall loss polynomial function.

\begin{tabular}{rrr}
\hline & $d_{\mathrm{p}}<32 \mathrm{~nm}$ & $d_{\mathrm{p}} \geq 32 \mathrm{~nm}$ \\
$A_{0}$ & $1.6129 \times 10^{-4}$ & $1.0665 \times 10^{-4}$ \\
$A_{1}$ & $-2.1192 \times 10^{-6}$ & $-2.1849 \times 10^{-6}$ \\
$A_{2}$ & $-2.1259 \times 10^{-8}$ & $3.1574 \times 10^{-8}$ \\
$A_{3}$ & 0 & $-1.7588 \times 10^{-10}$ \\
$A_{4}$ & 0 & $4.2589 \times 10^{-13}$ \\
$A_{5}$ & 0 & $-3.7557 \times 10^{-16}$ \\
\hline
\end{tabular}

rates. To achieve this, model was run iteratively to minimize the function

$f\left(\boldsymbol{n}_{\text {model }}, \boldsymbol{n}_{\text {meas }}\right)=\left\|\log 10\left(\boldsymbol{n}_{\text {model }}\right)-\log 10\left(\boldsymbol{n}_{\text {meas }}\right)\right\|$,

where

$\boldsymbol{n}_{\text {model }}=n_{i, j, \text { model }}, i=1 \ldots N_{i}, j=1 \ldots N_{j}$

and

$\boldsymbol{n}_{\text {meas }}=n_{i, j, \text { meas }}, i=1 \ldots N_{i}, j=1 \ldots N_{j}$

are the modeled and measured number concentrations, respectively. $N_{i}$ is the number of optimized size classes $i$, and $N_{j}$ is the number of time steps $j$. When using the logarithm of number concentrations instead of absolute number concentrations in Eq. (7), the wall losses of the largest and smallest particles (which have low number concentration) have larger weight in the optimization. Thus, the wall losses of those particles can be better optimized.

Equation (7) is fully empirical and includes all removal processes for the particles. It has to be noted that the function applies only for size range between $10 \mathrm{~nm}$ and $1 \mu \mathrm{m}$ and for the chamber used in our study.

Coagulation and hydration routines were simulated as in the default configuration of SALSA. A detailed description of the methods used to solve coagulation and hydration is given by Kokkola et al. (2008).

Since the nucleation mechanisms are not known in oxidation chamber experiments, nucleation was not explicitly modeled but the number concentrations measured in the two smallest size channels of SMPS were read into the model throughout the simulation. This way we were able to correctly describe the first steps of new particle formation without knowledge of the nucleation mechanism.

\section{Results and discussion}

\subsection{Gas-wall equilibrium partitioning}

In the first chamber experiment, three organic gases of different volatilities were injected into the Teflon chamber. The gas-wall equilibrium as a function of saturation vapor pressure of the OVOCs was determined by measuring the fraction of the injected compounds remaining in the gas phase (see Sect. 2.1 for the experiment setup). In this experiment, constant amounts of $\alpha$-pinene, nopinone, and pinanediol were simultaneously injected into the chamber at $30 \mathrm{~min}$ intervals for the duration of $3 \mathrm{~h}$. The motivation for such an experiment was to evaluate if and on what timescale, a steady-state equilibrium between the walls and the gas is reached. This way we were also able to determine if the walls were saturated at some point, thus affecting the equilibrium between the walls and the gas, or if the fractions of compounds partitioned on the chamber walls were independent of total amounts of the compounds in the chamber.

Figure $2 \mathrm{a}$ illustrates the observed evolution of the gas phase concentrations during the experiment. The concentrations in the figure are smoothed over $10 \mathrm{~s}$ periods. Equilibrium concentrations for all three measured compounds were reached within minutes after each injection, after which the concentration remained approximately constant. This clearly demonstrates that the chamber walls do not act as a continuous sink for the injected compounds.

As the deposition of the compounds to the chamber walls is a dynamical process, deposition of each organic compound $\mathrm{OC}$ was assumed to follow the equation

$\frac{\mathrm{d}[\mathrm{OC}]_{\mathrm{w}}}{\mathrm{d} t}=k\left[\left(\frac{K_{\mathrm{p}}}{\left(K_{\mathrm{p}}+1\right)}\right)[\mathrm{OC}]_{\mathrm{T}}-[\mathrm{OC}]_{\mathrm{w}}\right]$,

where $k\left(\mathrm{~s}^{-1}\right)$ is the mass transfer coefficient, i.e. a parameter that dictates the characteristic time for reaching the equilibrium between the walls and the chamber. The fraction of OC on the wall was determined as the difference between the known total amount of OC injected in the chamber $[\mathrm{OC}]_{\mathrm{T}}$ and the observed gas phase concentration after the concentration level was stabilized.

We estimated the equilibration time by solving analytically the wall concentration $[\mathrm{OC}]_{\mathrm{W}}$ from Eq. (11) and then optimizing the mass transfer coefficient $k$ so that evolution of $[\mathrm{OC}]_{\mathrm{W}}$ as a function of time matched the measured evolution of $[\mathrm{OC}]_{\mathrm{w}}$ for each injection. The mass transfer coefficient was optimized using an unconstrained nonlinear optimization method (Nelder and Mead, 1965). The optimization was done for 500 measurement points of gas phase concentrations starting from the peak values.

Due to significant noise in the PTR-MS-measured concentrations, the fitted values for $k$ ranged greatly between the injections, and our measurements were able to provide only a qualitative estimate of the mass transfer rate. For nopinone, the fitted $k$ values ranged from 0.03 to $0.79 \mathrm{~s}^{-1}$. Figure 2 includes the measured gas phase concentration as a function of time for one injection case (middle panel) together with the theoretical curve calculated according to Eq. (11) using a mass transfer coefficient with a value of $0.03 \mathrm{~s}^{-1}$. As can be seen in Fig. 2, using this value, the equilibrium is reached 

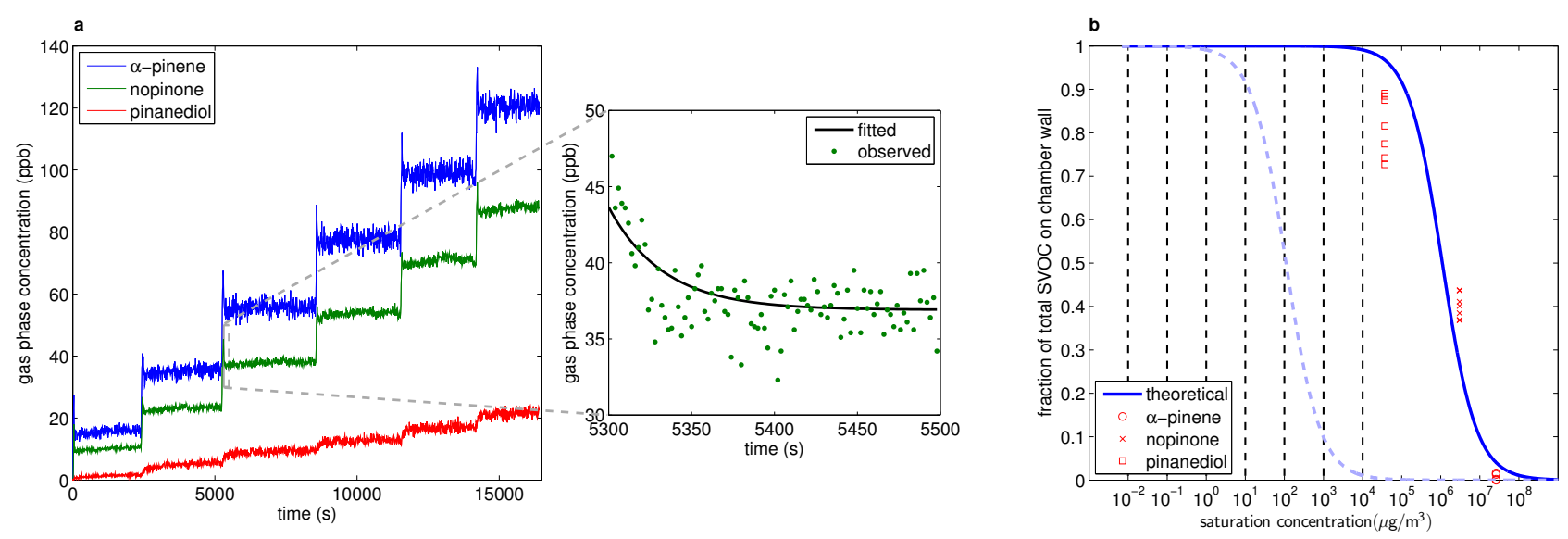

Fig. 2. (a) Time-dependent gas phase concentration of $\alpha$-pinene, nopinone, and pinanediol. (b) Measured fractions of the same three compounds on chamber walls (red symbols), a theoretical extrapolation of the measurements to other volatilities (blue solid curve), and a theoretical wall fraction assuming four orders of magnitude lower value for $C_{\mathrm{w}}$ (blue dashed curve). The vertical dashed lines indicate the commonly assumed VBS volatility bins.

in approximately $4 \mathrm{~min}$. In the study by Matsunaga and Ziemann (2010) n-Alkanes, 2-Alcohols, and 1-Alkenes reached equilibrium in timescales of more than $1 \mathrm{~h}$. However, for 2Ketones, the equilibrium was reached within $25 \mathrm{~min}$, which was the first observation instance. Since the mass transfer rates determined in our study result in much shorter equilibration times than those estimated by Matsunaga and Ziemann (2010) (for most compounds in their study), we use the lowest value in the model simulations that are described later in this manuscript. In addition, the peak in measured gas phase concentrations of $\alpha$-pinene indicates that the mixing of VOCs in the chamber affect the time evolution of concentrations after the injection. This causes uncertainty in the estimated equilibration rates since the effect of mixing and wall partitioning on gas phase concentration can not be separated. While the mixing of the SVOCs in the chamber affects the gas phase concentration, it can be assumed that the equilibrium is reached within the mixing time. If the equilibration did not occur within the mixing time, the gas phase concentrations would not stabilize before the equilibrium is reached.

For pinanediol, there was no distinct peak in the gas phase concentration during the injection; instead the concentration slowly increased to its new equilibrium value. Because of this, the mass transfer coefficient could not be determined. There is a possibility that pinanediol partitions to the wall or to undetected particles from which it gradually evaporates. However, the implication of this behavior is that pinanediol also reaches an equilibrium within a couple of minutes. Thus we can justify using the nopinone's equilibration rate for pinanediol as well.

We also tested if the simultaneous injection of these compounds would affect their equilibrium concentrations by injecting the gases sequentially into the chamber. However, no changes were observed in the equilibrium concentrations.
Figure $2 \mathrm{~b}$ shows the fraction of total injected mass of $\alpha$ pinene, nopinone, and pinanediol that were deposited on the chamber walls after each injection as a function of saturation concentration of the compounds. The mean fractions were 0.40 and 0.82 for nopinone and pinanediol, respectively. According to the measurement, $\alpha$-pinene remained completely in the gas phase. Large variability in the measured concentrations resulted in large variability in the estimated wall fractions of each compound. This was especially the case for pinanediol for which the measured gas phase concentration was of the same order as its variability. However, we found no correlation between the wall fraction and the total concentration of any of the compounds, indicating that the Henry's law type of equilibrium assumption holds for these concentrations. This also indicates that the chamber walls were not saturated with respect to the depositing gases at any point of the experiment.

Based on these measured values and Eqs. (1) and (2), we calculated a theoretical fraction of OC on the chamber walls as a function of saturation concentration. Equation (1) requires knowledge about the effective concentration of the absorbing mass $\left(C_{\mathrm{w}}\right)$, which is dependent on the properties of each compound (Matsunaga and Ziemann, 2010). We assumed $C_{\mathrm{w}}$ to be equal for all oxidation products of $\alpha$-pinene and set it to $1.1 \times 10^{3} \mathrm{mg} \mathrm{m}^{-3}$, which is the average value for nopinone and pinanediol in our wall loss experiments, determined from Eqs. (1) and (2). Using this value, we calculated the theoretical fraction of OC partitioning to the walls as a function of saturation concentration (solid blue curve in Fig. 2b. The dashed vertical lines in Fig. $2 b$ show the saturation concentrations for typically used volatility classes in VBS (Pathak et al., 2007a). Although the wall fractions of individual compounds do not fall exactly on the theoretical curve, we use this as a first-order approximation for 
equilibrium partitioning later in our aerosol microphysics modeling. Based on this theoretical curve we can see that for all the VBS volatility classes, practically all OC should be on the chamber walls once equilibrium between the gas phase and the walls is formed.

This equilibrium assumption holds only in a chamber with no aerosol particles. In a chamber with particles, the partitioning between the gas, particles, and wall is a kinetic process where the mass transfer rates determine where the condensing species are partitioned.

It should be noted that the assumption of constant $C_{\mathrm{w}}$ for all compounds can not be considered fully valid. Matsunaga and Ziemann (2010) have demonstrated that the value of $C_{\mathrm{w}}$ differs depending on the functional groups of condensing compounds. Since no data for $C_{\mathrm{w}}$ of $\alpha$-pinene oxidation products are available, we have to consider this assumption as the best estimate. In addition, the value of $C_{\mathrm{w}}$ in our study is two to three orders of magnitude higher compared to those determined by Matsunaga and Ziemann (2010). However, the wall partitioning of the lowest volatility classes, which is the main focus of our study, is not very sensitive to this value. For example, if $C_{\mathrm{w}}$ was reduced by four orders of magnitude, the wall-partitioning curve would shift left by $10^{-4}$. This is illustrated by the dashed blue curve in Fig. 2. It can be seen from the figure that the wall fraction would still be close to unity for the volatility classes that can grow the freshly nucleated particles (i.e. the two leftmost volatility classes). It can also be seen that this curve does not correspond to the observed wall fractions at all.

As can be seen from Fig. 2b, the compounds used in our study have higher volatility than commonly used VBS volatility classes. This is because our method of measuring gaseous wall losses requires that there is no new particle formation from low volatile compounds during an experiment. For the organic gases used in this study, we did not observe a significant number of particles during the measurement. However, we also carried out a similar experiment as described above for cis-pinonic acid, which has a saturation concentration of the order of $10^{2} \mu \mathrm{g} \mathrm{m}^{-3}$ (Bilde and Pandis, 2001); i.e. an order of magnitude lower than that of pinanediol. In this experiment there was significant formation of new particles which prevented the estimation of the OVOC's equilibrium wall losses. Therefore, using the method presented in this study, we are unable to determine experimentally the wall losses for the commonly used VBS classes. To verify that the theoretical curve in Fig. $2 b$ applies to the whole range of volatilities, new methods for measuring the wall fraction of low volatility organic gases would be needed.

\subsection{SOA formation experiment}

Next, we applied the volatility-dependent wall loss function Eq. (11) to the aerosol microphysics model to investigate the implications of gas-phase wall losses in a SOA formation
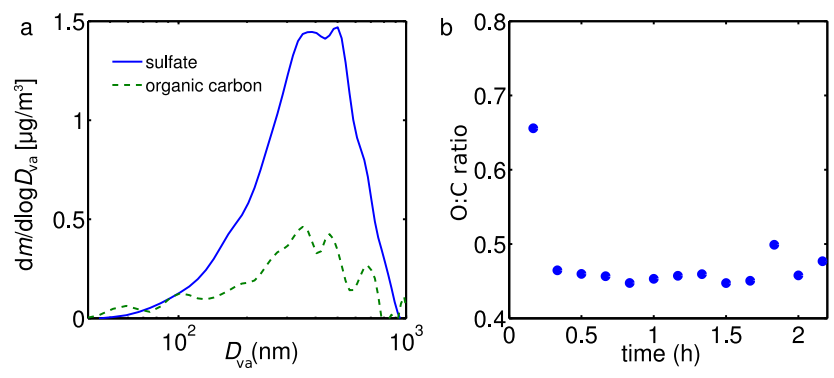

Fig. 3. (a) Mass size distribution $\mathrm{d} m / \mathrm{d} \log D_{\mathrm{va}}\left(\mu \mathrm{g} \mathrm{m}^{-3}\right)$ of sulfate (blue curve) and organic carbon (green curve) as a function of vacuum aerodynamic diameter $D_{\mathrm{va}}$. (b) 10 min mean oxygen to carbon radio $(\mathrm{O}: \mathrm{C})$ during the first $2 \mathrm{~h}$ after the injection of ozone in the chamber.

chamber experiment. In this experiment ammonium sulfate seed aerosol was fed into the chamber followed by an injection of $\alpha$-pinene and ozone. Figure 3a illustrates the $2 \mathrm{~h}$ average mass size distribution measured by AMS. Figure $3 b$ shows the development of oxygen to carbon ratio $(\mathrm{O}: \mathrm{C})$ during the same period as a function of time. The $\mathrm{O}: \mathrm{C}$ ratio in Fig. $3 \mathrm{~b}$ was averaged over 10 min sequences. In addition, Fig. 4a illustrates the measured evolution of the aerosol size distribution during the experiment.

From Fig. 4a we can see that after the injection of $\alpha$ pinene and ozone, a new particle formation event occurs and a distinct new Aitken mode of small particles appears in the size distribution. Since the nucleation-sized particles grow to $10 \mathrm{~nm}$ within a few minutes of the injection of ozone, it is evident that a significant amount of LVOCs capable of growing nanometer-sized particles form in the chamber during the first steps of alpha-pinene oxidation.

The composition of larger $\left(d_{\mathrm{p}}>40 \mathrm{~nm}\right)$ particles was measured using an aerosol mass spectrometer (AMS) throughout the experiment. According to the measurements, when the Aitken mode appears in the size distribution, organic mass fraction in the total aerosol rapidly increased to approximately 0.3 .

According to the AMS mass size distribution (Fig. 3a), the newly formed mode of particles with $d_{\mathrm{p}}<80 \mathrm{~nm}$ is mainly composed of organics. During the formation of the new mode, the $\mathrm{O}: \mathrm{C}$ ratio peaks at 0.65 , after which it levels to the value of 0.45 . According to previous studies (Jimenez et al., 2009), such an $\mathrm{O}: \mathrm{C}$ ratio indicates that the condensed organics are of fairly low volatility. As this is the mean $\mathrm{O}: \mathrm{C}$ of the total sampled aerosol mass, there is a possibility that a fraction of condensing matter is of very low volatility.

\subsection{Modeling the SOA formation experiment}

To evaluate the role of wall losses and the contribution of OVOCs of different volatilities to the evolution of aerosol size distribution, this SOA formation experiment was simulated using the aerosol microphysics code SALSA (Kokkola 
et al., 2008). The model was initialized with size distribution measured in the chamber with SMPS prior to the injection of ozone. The initial aerosol surface area concentration was $416 \mu \mathrm{m}^{2} \mathrm{~cm}^{-} 3$ and the mean geometric diameter was approximately $70 \mathrm{~nm}$.

In the first simulation, we assumed stoichiometric coefficients given in Table 1 (Pathak et al., 2007a) for the gas-phase reaction between $\alpha$-pinene and ozone. Based on the wall loss experiments, we assumed that the mass transfer coefficient to the walls is $0.03 \mathrm{~s}^{-1}$ for all volatility classes.

The left panel of Fig. 4b shows the modeled evolution of the aerosol size distribution. The right panel shows the modeled (solid line) and measured size distribution (dashed line) $1.5 \mathrm{~h}$ into the simulation. In this simulation, the formation of SOA was found to be too low to reproduce the growth of the nucleation mode particles. This indicates too low values for the stoichiometric coefficients in this simulation.

To reproduce the growth, we optimized the value for the stoichiometric coefficients of the lowest volatility class using an unconstrained nonlinear optimization method (Nelder and Mead, 1965). Similarly to the optimization of wall loss parameters, the model was run iteratively to minimize Eq. (8). This time, the optimization was done only for size classes below $40 \mathrm{~nm}$ in diameter. The two smallest size classes were omitted in the optimization, as they were read directly from the SMPS measurements to be used as an input for the model (see Sect. 2.3).

The optimization resulted in significantly higher stoichiometric coefficient for the lowest volatility class; our optimized value was 0.14 , which is approximately two orders of magnitude higher than the original value of 0.001 . When we used the optimized values, the model was able to simulate the formation of the Aitken mode as can be seen from Fig. 4c (left and right panel). However, when we used the optimized stoichiometric coefficient there was noticeable evaporation of SOA approximately $2.5 \mathrm{~h}$ into the simulation, which was not seen in the measured size distribution. Our simulation indicates that compounds with equilibrium concentrations of the order of $10^{-2} \mu \mathrm{g} \mathrm{m}^{3}$ will evaporate from particles of tens of nanometers. However, there is a possibility that SVOC reacts in the particle phase, which would decrease its saturation concentration significantly, making it very low volatile. It has been also suggested that SOA particles are amorphous (Virtanen et al., 2010), resulting a decrease in evaporation rate due to the diffusional limitations in the particle bulk (Cappa and Jimenez, 2010; Vaden et al., 2010; Abramson et al., 2013).

To improve the consistency between measurements and model, we added the volatility of the lowest VBS class as an optimization parameter and repeated the optimization. When we optimized the volatility and the stoichiometric coefficient concurrently, the best fit was obtained when the equilibrium concentration was $2.5 \times 10^{-5} \mu \mathrm{g} \mathrm{m}^{-3}$ and the stoichiometric coefficient was 0.1 . We can see from Fig. $4 \mathrm{~d}$ (left and right panel) that when using these values, the agreement between the measured and modeled size distribution increased even further. With these values, there was no evaporation of the Aitken mode particles.

Compounds of such low volatility would be difficult to observe in chamber measurements due to their wall losses. According to our model simulation, in which the volatility of the OVOC of the lowest volatility was assumed to be $2.5 \times 10^{-5} \mu \mathrm{g} \mathrm{m}^{-3}$, approximately $60 \%$ of its total amount was deposited on the chamber walls already when the new particle formation was detected. By the end of the experiment, approximately $95 \%$ of this lowest volatility compound was deposited on the chamber walls. The dominant role of the wall deposition strongly affects the mass yields measured in the chamber. When we reran the same simulation without wall losses of the organic gases, the mass yield was approximately 4 times higher.

Because of the competition between particle and wall partitioning, the ratio between the surface area of the chamber and the seed particles will affect the measured yield. As explained in Sect. 3.1, the partitioning of condensing species between the wall and particles is defined by mass transfer kinetics. The rate at which condensing compounds partition to particles is essentially determined by the condensation sink (Kulmala et al., 2001), which is defined as

$C S=4 \pi D \sum_{i} \beta_{m, i} r_{i} N_{i}$

where $D$ is the diffusion coefficient, $i$ is the particle size class, $\beta_{m, i}$ is the transitional correction factor (Fuchs and $\mathrm{Su}-$ tugin, 1971), $r_{i}$ is the particle radius, and $N_{i}$ is the number concentration.

For gas-wall partitioning of non-volatile and low-volatile compounds, the parameter corresponding to the condensation sink is the mass transfer rate $k$ (see Eq. 11). Since the wall partitioning depletes some of the VOCs, the condensation sink and the mass transfer rate determine how the condensing matter is divided between the particles and the wall. The ratio between the mass transfer rate $k$ and the condensation sink provides a rough estimate of the amount for mass lost on the walls. Thus, the same ratio can also be used for correcting yields of LVOCs. In our experiment, this ratio was approximately 3.8 during the formation of the new mode which corresponds to the difference between the simulations with and without wall losses (ratio of 4).

There remains large uncertainty in the estimated mass transfer rate and its value can significantly affect the modeled amount of organics condensed on the particle. As can be seen in the middle panel of Fig. 2, using the value of $0.03 \mathrm{~s}^{-1}$, the equilibration timescale is of the order of $4 \mathrm{~min}$. The model was also tested by decreasing the equilibration rate by half, which increased the equilibration time to approximately $8 \mathrm{~min}$. In this test, wall losses reduced the growth of the Aitken mode significantly (not shown here). The underestimation of the yield also was reduced. With double the equilibration time, the amount of SOA in the particles was 1.6 times higher compared to the simulation with 

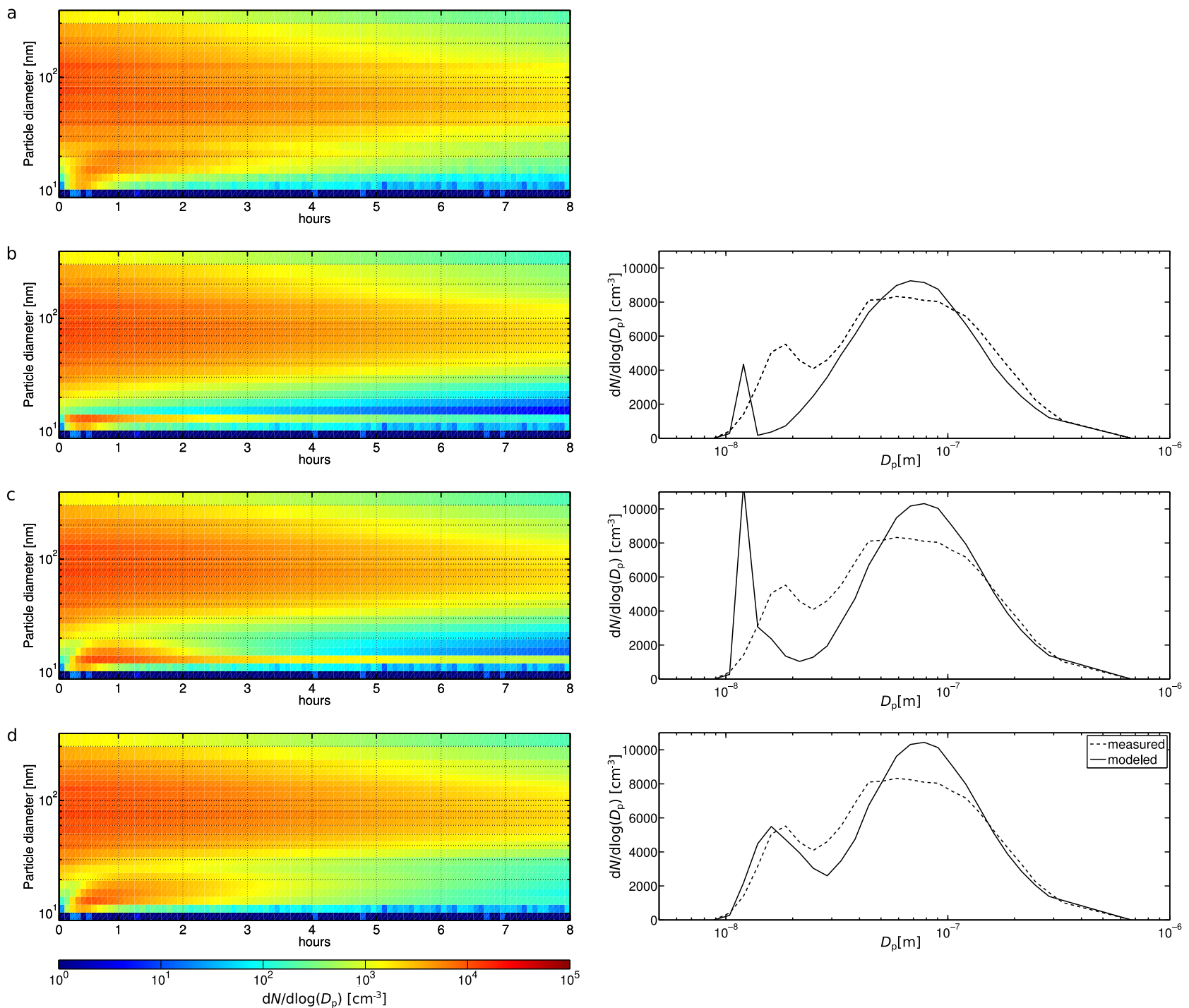

Fig. 4. (a) Observed evolution of aerosol size distribution, (b) modeled evolution of aerosol size distribution using stoichiometric coefficients given in Table 1, (c) modeled evolution of aerosol size distribution using optimized stoichiometric coefficient for the lowest volatility class, (d) modeled evolution of aerosol size distribution using optimized volatility and stoichiometric coefficient for the lowest volatility class. The right column includes a 2-dimensional size distribution of each simulation at $1.5 \mathrm{~h}$ into the simulation.

the equilibration rate of $0.03 \mathrm{~s}^{-1}$. However, this would still amount to a significant underestimation of the yield of lowvolatile compounds.

As the mass size distribution confirms (Fig. 3), the newly formed mode is mainly composed of organic matter. The fraction of organic gases that is lost on the walls in chamber would, in the atmosphere, amount to a significant fraction of the aerosol mass as there would not be a similar sink for the condensing OVOCs. This additional condensing matter would significantly affect the number of particles that can act as cloud condensation nuclei (CCN).

It should be noted that our model describes the gas phase chemistry and aerosol processes in a simplified manner and can only qualitatively simulate aerosol growth process. There can also be other mechanisms that would explain the fact that evaporation of the Aitken mode is not seen in the measurements. For example, particle phase diffusion and chemical transformation are not included in the model, which could potentially have significant effects on evolution of the aerosol size distribution. In addition, if the condensed-phase OVOCs behave distinctly differently from ideal compounds (i.e. the activity coefficient is significantly less than unity), the saturation concentration would not have to be as low as $2.5 \times 10^{-5} \mu \mathrm{g} \mathrm{m}^{-3}$.

Our study does not confirm or rule out the possibility of LVOC formation in the gas phase. In a previous study Ehn et al. (2012) observed extremely oxidized pinene reaction products in chamber and ambient conditions. In their study, 
they suggest that highly oxidized compounds are formed in the gas phase rather than the particle phase.

\section{Conclusions}

We have analyzed a new particle formation event in a chamber to probe the gas-particle partitioning of organic vapors of different volatilities. To our knowledge, this is the first study where wall losses of condensing organics are treated depending on their volatility when modeling chamber experiments. By comparing the observed rates of wall deposition and initial particle growth to a detailed aerosol dynamics simulation, we arrived at the following main conclusions:

1. To comprehensively determine the aerosol mass yields for OVOC of different volatilities in Teflon chamber studies, the wall losses of gas phase OVOC should be carefully accounted for, taking into consideration their volatility. Because of the rapid depletion of OVOC of lowest volatilities to the chamber walls, their yields can be significantly underestimated. In our simulation of a chamber experiment in which SOA was formed on pre-existing ammonium sulfate aerosol, we estimated that the aerosol mass yield can be underestimated up to a factor of four.

2. Organic compounds with very low volatility are likely formed rapidly in a chamber where $\alpha$-pinene and ozone are present. These compounds are responsible for a significant fraction of the observed early growth. If they are formed in the gas phase, they deposit on the walls very quickly and the growth of newly formed particles is significantly inhibited. According to our model simulations, the observed nucleation mode growth in the presence of vapor wall losses necessitates the inclusion of a significant amount of organics of very low volatility. Optimizing model agreement with measurements suggests volatilities of the order of $10^{-5} \mathrm{gg} \mathrm{m}^{-3}$.

3. At ambient conditions, the key implication of our study is increased mass yield from low-volatile compounds that can contribute significantly to the number concentration of nucleated particles growing to sizes that can take part in cloud activation. At the same time, the majority of these LVOCs condense on the larger particles, contributing to the growth and evolution of the entire aerosol distribution.
Acknowledgements. This work was supported by the Maj and Tor Nessling Foundation (Project no. 2012358), the Academy of Finland (projects nr. 252908 and 138951), the Academy of Finland Centre of Excellence Program (project no. 1118615), and the strategic funding of the University of Eastern Finland.

Edited by: G. McFiggans

\section{References}

Abramson, E., Imre, D., Beránek, J., Wilson, J., and Zelenyuk, A.: Experimental determination of chemical diffusion within secondary organic aerosol particles, Phys. Chem. Chem. Phys., 15, 2983-2991, 2013.

Aiken, A. C., DeCarlo, P. F., Kroll, J. H., Worsnop, D. R., Huffman, J. A., Docherty, K. S., Ulbrich, I. M., Mohr, C., Kimmel, J. R., Sueper, D., Sun, Y., Zhang, Q., Trimborn, A., Northway, M., Ziemann, P. J., Canagaratna, M. R., Onasch, T. B., Alfarra, M. R., Prevot, A. S. H., Dommen, J., Duplissy, J., Metzger, A., Baltensperger, U., and Jimenez, J. L.: O/C and OM/OC Ratios of Primary, Secondary, and Ambient Organic Aerosols with HighResolution Time-of-Flight Aerosol Mass Spectrometry, Environ. Sci. Technol., 42, 4478-4485, doi:10.1021/es703009q, 2008.

Atkinson, R. and Arey, J.: Gas-phase tropospheric chemistry of biogenic volatile organic compounds: a review, Atmos. Environ., 37, S197-S219, 2003.

Bilde, M. and Pandis, S.: Evaporation rates and vapor pressures of individual aerosol species formed in the atmospheric oxidation of alpha- and beta-pinene, Environ. Sci. Technol., 35, 3344-3349, 2001.

Cappa, C. D. and Jimenez, J. L.: Quantitative estimates of the volatility of ambient organic aerosol, Atmos. Chem. Phys., 10, 5409-5424, doi:10.5194/acp-10-5409-2010, 2010.

Ceulemans, K., Compernolle, S., and Müller, J.-F.: Parameterising secondary organic aerosol from $\alpha$-pinene using a detailed oxidation and aerosol formation model, Atmos. Chem. Phys., 12, 5343-5366, doi:10.5194/acp-12-5343-2012, 2012.

DeCarlo, P. F., Kimmel, J. R., Trimborn, A., Northway, M. J., Jayne, J. T., Aiken, A. C., Gonin, M., Fuhrer, K., Horvath, T., Docherty, K. S., Worsnop, D. R., and Jimenez, J. L.: Field-Deployable, High-Resolution, Time-of-Flight Aerosol Mass Spectrometer, Anal. Chem., 78, 8281-8289, doi:10.1021/ac061249n, 2006.

Donahue, N. M., Robinson, A. L., Stanier, C. O., and Pandis, S. N.: Coupled Partitioning, Dilution, and Chemical Aging of Semivolatile Organics, Environ. Sci. Technol., 40, 2635-2643, doi:10.1021/es052297c, pMID: 16683603, 2006.

Duplissy, J., DeCarlo, P. F., Dommen, J., Alfarra, M. R., Metzger, A., Barmpadimos, I., Prevot, A. S. H., Weingartner, E., Tritscher, T., Gysel, M., Aiken, A. C., Jimenez, J. L., Canagaratna, M. R., Worsnop, D. R., Collins, D. R., Tomlinson, J., and Baltensperger, U.: Relating hygroscopicity and composition of organic aerosol particulate matter, Atmos. Chem. Phys., 11, 11551165, doi:10.5194/acp-11-1155-2011, 2011.

Ehn, M., Kleist, E., Junninen, H., Petäjä, T., Lönn, G., Schobesberger, S., Dal Maso, M., Trimborn, A., Kulmala, M., Worsnop, D. R., Wahner, A., Wildt, J., and Mentel, Th. F.: Gas phase formation of extremely oxidized pinene reaction products in chamber and ambient air, Atmos. Chem. Phys., 12, 5113-5127, doi:10.5194/acp-12-5113-2012, 2012. 
Fuchs, N. A. and Sutugin, A. G.: International reviews in aerosol physics and chemistry: Topics in current aerosol research, Part 2, chap. Highly dispersed aerosols, 1-200, Pergamon, 1971.

Goldstein, A. H. and Galbally, I. E.: Known and Unexplored Organic Constituents in the Earth's Atmosphere, Environ. Sci. Technol., 41, 1514-1521, doi:10.1021/es072476p, 2007.

Hallquist, M., Wenger, J. C., Baltensperger, U., Rudich, Y., Simpson, D., Claeys, M., Dommen, J., Donahue, N. M., George, C., Goldstein, A. H., Hamilton, J. F., Herrmann, H., Hoffmann, T., Iinuma, Y., Jang, M., Jenkin, M. E., Jimenez, J. L., Kiendler-Scharr, A., Maenhaut, W., McFiggans, G., Mentel, Th. F., Monod, A., Prévôt, A. S. H., Seinfeld, J. H., Surratt, J. D., Szmigielski, R., and Wildt, J.: The formation, properties and impact of secondary organic aerosol: current and emerging issues, Atmos. Chem. Phys., 9, 5155-5236, doi:10.5194/acp-9-51552009, 2009.

Hao, L. Q., Romakkaniemi, S., Yli-Pirilä, P., Joutsensaari, J., Kortelainen, A., Kroll, J. H., Miettinen, P., Vaattovaara, P., Tiitta, P., Jaatinen, A., Kajos, M. K., Holopainen, J. K., Heijari, J., Rinne, J., Kulmala, M., Worsnop, D. R., Smith, J. N., and Laaksonen, A.: Mass yields of secondary organic aerosols from the oxidation of $\alpha$-pinene and real plant emissions, Atmos. Chem. Phys., 11, 1367-1378, doi:10.5194/acp-11-1367-2011, 2011.

Jacobson, M. Z.: Fundamentals of Atmospheric Modeling, Second Edition, Cambridge University Press, New York, 2005.

Jayne, J. T., Leard, D. C., Zhang, X., Davidovits, P., Smith, K. A., Kolb, C. E., and Worsnop, D. R.: Development of an Aerosol Mass Spectrometer for Size and Composition Analysis of Submicron Particles, Aerosol Sci. Tech., 33, 49-70, 2000.

Jimenez, J. L., Canagaratna, M. R., Donahue, N. M., Prevot, A. S. H., Zhang, Q., Kroll, J. H., DeCarlo, P. F., Allan, J. D., Coe, H., Ng, N. L., Aiken, A. C., Docherty, K. S., Ulbrich, I. M., Grieshop, A. P., Robinson, A. L., Duplissy, J., Smith, J. D., Wilson, K. R., Lanz, V. A., Hueglin, C., Sun, Y. L., Tian, J., Laaksonen, A., Raatikainen, T., Rautiainen, J., Vaattovaara, P., Ehn, M., Kulmala, M., Tomlinson, J. M., Collins, D. R., Cubison, M. J., E., Dunlea, J., Huffman, J. A., Onasch, T. B., Alfarra, M. R., Williams, P. I., Bower, K., Kondo, Y., Schneider, J., Drewnick, F., Borrmann, S., Weimer, S., Demerjian, K., Salcedo, D., Cottrell, L., Griffin, R., Takami, A., Miyoshi, T., Hatakeyama, S., Shimono, A., Sun, J. Y., Zhang, Y. M., Dzepina, K., Kimmel, J. R., Sueper, D., Jayne, J. T., Herndon, S. C., Trimborn, A. M., Williams, L. R., Wood, E. C., Middlebrook, A. M., Kolb, C. E., Baltensperger, U., and Worsnop, D. R.: Evolution of Organic Aerosols in the Atmosphere, Science, 326, 1525-1529, doi:10.1126/science.1180353, 2009.

Kokkola, H., Korhonen, H., Lehtinen, K. E. J., Makkonen, R., Asmi, A., Järvenoja, S., Anttila, T., Partanen, A.-I., Kulmala, M., Järvinen, H., Laaksonen, A., and Kerminen, V.-M.: SALSA - a Sectional Aerosol module for Large Scale Applications, Atmos. Chem. Phys., 8, 2469-2483, doi:10.5194/acp-8-2469-2008, 2008.

Kroll, J. H. and Seinfeld, J. H.: Chemistry of secondary organic aerosol: Formation and evolution of low-volatility organics in the atmosphere, Atmos. Environ., 42, 3593-3624, doi:10.1016/j.atmosenv.2008.01.003, 2008.

Kulmala, M., Dal Maso, M., Mäkelä, J. M., Pirjola, L., Väkevä, M., Aalto, P., Miikkulainen, P., Hämeri, K., and O'Dowd, C. D.: On the formation, growth and composition of nucle- ation mode particles, Tellus B, 53, 479-490, doi:10.1034/j.16000889.2001.530411.x, 2001.

Loza, C. L., Chan, A. W. H., Galloway, M. M., Keutsch, F. N., Flagan, R. C., and Seinfeld, J. H.: Characterization of Vapor Wall Loss in Laboratory Chambers, Environ. Sci. Technol., 44, 50745078, 2010.

Matsunaga, A. and Ziemann, P. J.: Gas-Wall Partitioning of Organic Compounds in a Teflon Film Chamber and Potential Effects on Reaction Product and Aerosol Yield Measurements, Aerosol Sci Tech., 44, 881-892, doi:10.1080/02786826.2010.501044, 2010.

Meyer, N. K., Duplissy, J., Gysel, M., Metzger, A., Dommen, J., Weingartner, E., Alfarra, M. R., Prevot, A. S. H., Fletcher, C., Good, N., McFiggans, G., Jonsson, Å. M., Hallquist, M., Baltensperger, U., and Ristovski, Z. D.: Analysis of the hygroscopic and volatile properties of ammonium sulphate seeded and unseeded SOA particles, Atmos. Chem. Phys., 9, 721-732, doi:10.5194/acp-9-721-2009, 2009.

Nelder, J. A. and Mead, R.: A Simplex Method for Function Minimization, The Comput. J., 7, 308-313, doi:10.1093/comjnl/7.4.308, 1965.

Odum, J. R., Hoffmann, T., Bowman, F., Collins, D., Flagan, R. C., and Seinfeld, J. H.: Gas/Particle Partitioning and Secondary Organic Aerosol Yields, Environ. Sci. Technol., 30, 2580-2585, doi:10.1021/es950943+, 1996.

Pathak, R. K., Presto, A. A., Lane, T. E., Stanier, C. O., Donahue, N. M., and Pandis, S. N.: Ozonolysis of $\alpha$-pinene: parameterization of secondary organic aerosol mass fraction, Atmos. Chem. Phys., 7, 3811-3821, doi:10.5194/acp-7-3811-2007, 2007a.

Pathak, R. K., Stanier, C. O., Donahue, N. M., and Pandis, S. N.: Ozonolysis of alpha-pinene at atmospherically relevant concentrations: Temperature dependence of aerosol mass fractions (yields), J. Geophys. Res., 112, 2156-2202, doi:10.1029/2006JD007436, 2007b.

Pierce, J. R., Engelhart, G. J., Hildebrandt, L., Weitkamp, E. A., Pathak, R. K., Donahue, N. M., Robinson, A. L., Adams, P. J., and Pandis, S. N.: Constraining Particle Evolution from Wall Losses, Coagulation, and Condensation-Evaporation in SmogChamber Experiments: Optimal Estimation Based on Size Distribution Measurements, Aerosol Sci. Tech., 42, 1001-1015, doi:10.1080/02786820802389251, 2008.

Pierce, J. R., Riipinen, I., Kulmala, M., Ehn, M., Petäjä, T., Junninen, H., Worsnop, D. R., and Donahue, N. M.: Quantification of the volatility of secondary organic compounds in ultrafine particles during nucleation events, Atmos. Chem. Phys., 11, 90199036, doi:10.5194/acp-11-9019-2011, 2011.

Radhakrishnan, K. and Hindmarsh, A. C.: Description and use of LSODE, the Livermore Solver for Ordinary Differential Equations, LLNL Report UCRL-ID-113855, Lawrence Livermore National Laboratory, Livermore, California, 1993.

Riipinen, I., Pierce, J. R., Yli-Juuti, T., Nieminen, T., Häkkinen, S., Ehn, M., Junninen, H., Lehtipalo, K., Petäjä, T., Slowik, J., Chang, R., Shantz, N. C., Abbatt, J., Leaitch, W. R., Kerminen, V.-M., Worsnop, D. R., Pandis, S. N., Donahue, N. M., and Kulmala, M.: Organic condensation: a vital link connecting aerosol formation to cloud condensation nuclei (CCN) concentrations, Atmos. Chem. Phys., 11, 3865-3878, doi:10.5194/acp-11-38652011, 2011.

Vaden, T. D., Song, C., Zaveri, R. A., Imre, D., and Zelenyuk, A.: Morphology of mixed primary and secondary organic particles 
and the adsorption of spectator organic gases during aerosol formation, P. Natl. Acad. Sci. USA, 107, 6658-6663, 2010.

Virtanen, A., Joutsensaari, J., Koop, T., Kannosto, J., Yli-Pirila, P., Leskinen, J., Makela, J. M., Holopainen, J. K., Poschl, U., Kulmala, M., Worsnop, D. R., and Laaksonen, A.: An amorphous solid state of biogenic secondary organic aerosol particles, Nature, 467, 824-827, doi:10.1038/nature09455, 2010.

Vuorinen, T., Nerg, A.-M., Ibrahim, M. A., Reddy, G. V. P., and Holopainen, J. K.: Emission of Plutella xylostella-Induced Compounds from Cabbages Grown at Elevated $\mathrm{CO}_{2}$ and Orientation Behavior of the Natural Enemies, Plant Physiol., 135, 19841992, doi:10.1104/pp.104.047084, 2004.
Zhao, J., Ortega, J., Chen, M., McMurry, P. H., and Smith, J. N.: Dependence of particle nucleation and growth on high molecular weight gas phase products during ozonolysis of $\alpha$-pinene, Atmos. Chem. Phys. Discuss., 13, 9319-9354, doi:10.5194/acpd13-9319-2013, 2013. 